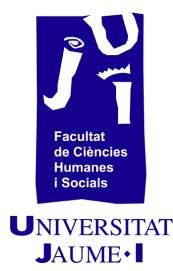

\title{
Comunicación financiera en la web de las ONG infantiles de Valencia
}

Cristina Aranda Amaré

Betsaida Calatayud Sospedra 


\section{Justificación del tema}

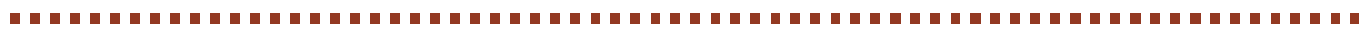

El trabajo que vamos a realizar para la asignatura de comunicación financiera consistirá en analizar la comunicación financiera de cada web de las ONG valencianas. La elección de nuestro tema ha surgido por los debates que actualmente el sector de las ONG está sufriendo. Periodistas como Pablo Herreros persiguen desmantelar las inversiones de las recaudaciones de algunas organizaciones. Se critica que el dinero recibido está siendo invertido en marketing y publicidad y no en la causa por la cual lucha la ONG. Por tanto, nuestro propósito es detectar aquellas organizaciones que están siendo totalmente transparentes con sus fondos financieros; si publican anualmente documentos verídicos sobre la procedencia del capital que han obtenido, en qué lo han invertido, si los movimientos económicos realizados tienen algún fin, etc.

\section{Objetivos}

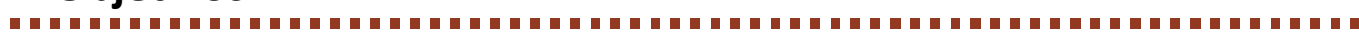

Los objetivos que queremos conseguir a través de la realización de este trabajo, son los siguientes: poder profundizar y llegar a conocer más a fondo el sector financiero de cada ONG infantil valenciana y cómo lo comunica, la procedencia del capital obtenido, el uso de dicho dinero y los resultados conseguidos mediante el movimiento de capital. Todos estos objetivos analizados mediante lo que podamos encontrar en su página web, para detectar las organizaciones fiables y transparentes con la sociedad.

\section{Hipótesis}

Las ONG infantiles que operan en Valencia son transparentes en materia de comunicación financiera a través de sus páginas web corporativas.

\section{Marco teórico}

\subsection{Estudios, autores y tesis}

Un estudio publicado el 15 de febrero de 2012 por dos profesoras de la Universidad de Málaga en la revista de comunicación Vivat Academia, trata sobre la comunicación digital de las organizaciones sociales en España.

En él se observa la utilidad que le dan las ONG españolas a Internet, a sus páginas web, redes sociales y blogs. Mediante el espacio cibernético, dan a conocer aquello que llevan a cabo, los 
apartados para socios, informan de sus campañas de captación o recaudación tanto de capital como de socios, etc. En ese estudio se han seleccionado las organizaciones sociales en las que el número de socios es mayor; Cruz Roja España, Médicos Sin Fronteras, Intermón Oxfam, Ayuda en Acción y UNICEF. La técnica de investigación empleada ha sido parecida a la del trabajo que perseguimos; el análisis del contenido de los sitios web, blog y RR. SS. Persiguen desmantelar a las organizaciones sociales que no están siendo responsables puesto que nos encontramos en un contexto en el que muchos grupos de interés padecen el descrédito de la ciudadanía y, por tanto, tanto organizaciones como movimientos sociales se han convertido en un exponente de participación ciudadana, pues estas deben de reflejar transparencia y dar voz a la sociedad afectada.

Internet ha sido una herramienta actual clave para las ONG españolas. Por eso, cada una de ellas, tanto grandes como pequeñas, disponen de página web mediante la cual poder relacionarse con su público objetivo. Además reflejan sus proyectos, sus ideas, su financiación... intentando captar nuevos socios a través de colaboraciones en su web. Una diferencia que se observa entre las páginas web de las grandes y las pequeñas empresas es que las pequeñas organizaciones sociales no recaudan capital mediante su web, mientras que las grandes ONG hacen uso de Internet para facilitar el ingreso de capital.

También se diferencian en la actualización de sus sitios web. Normalmente las grandes organizaciones sociales lo hacen con mayor frecuencia, mientras que las de menor capacidad, menos asiduamente. Por otra parte, unas disponen de blogs informativos y otras no, la presencia en redes sociales es más equilibrada, puesto que tanto unas como otras hacen uso de ellas para darse a conocer, para comunicarse con la sociedad y para reflejar su manera de actuar.

Basándonos en la edición de Joan Costa, DirCom, estratega de la complejidad: Nuevos paradigmas de la Dirección de Comunicación, detectamos que entre los apartados del libro habla sobre la comunicación financiera de las ONG, bajo información de Rafael López Lita. Se puede observar que está siendo objeto de estudio la creciente intervención de la comunicación financiera en las ONG motivada por la necesidad de financiación de estas.

Esto está ligado a la importancia de la transparencia, además de reflejar cuáles son sus costes reales de transformación, los resultados de sus intervenciones y la coherencia de sus programas. Es decir, sus movimientos financieros deben ser claros, transparentes y totalmente públicos. Las retribuciones y los gastos asociados a su personal deben de estar reflejados con claridad en sus memorias, de manera que las organizaciones sociales que confían fondos a su 
gestión se encuentren con ánimo de seguir en una misma línea de colaboración y, además, incrementarla.

La comunicación financiera influye en los hábitos de consumo y, por tanto, da lugar a una nueva cultura de consumo según Joan Costa. Su potencialidad abastece un amplio espacio, puesto que la dinamización de los mercados financieros será resultado del cambio cultural producido en la sociedad.

El autor llega a la conclusión de que la comunicación financiera está siendo influida por el contexto actual tan cambiante y observa los nuevos paradigmas de la comunicación financiera como los que tienen relación con la confianza frente a los casos de información financiera falsa o fraudulenta. Además, los derivados de introducir en sus metodologías los valores renovados que provienen de la importancia de productos financieros responsables cuyo emisor también se considera socialmente responsable, como dice Joan Costa, «han alcanzando cotas asumibles de rentabilidad, liquidez, seguridad y dignidad».

\subsection{Códigos deontológicos}

Un requisito que tienen que tener muy en cuenta las fundaciones es la transparencia, y cada vez lo es más para los donantes, los beneficiarios y para la sociedad. Una de las maneras mediante las cuales ser transparente es el reflejo preciso del trabajo realizado, de la manera en que lo hacen y de los recursos utilizados.

Una de las asociaciones que permite guiar de manera deontológica a las ONG es AEF, Asociación Española de Fundaciones; ofrece los instrumentos necesarios para alcanzar el compromiso y la transparencia que estas deben de aplicar de manera ética. El propósito de la asociación es facilitar a las fundaciones un documento en el que aparecen una serie de indicadores de transparencia. Este tipo de documento está elaborado de manera minuciosa y se revisa de periódicamente para que dichos indicadores se adecuen a la normativa vigente del momento $y$, además, se puedan conseguir los estándares exigidos de transparencia.

A continuación, presentamos los indicadores propuestos por AEF, extraídos de su página web:

\section{Constitución de la fundación y datos identificativos}
(a) Fecha de constitución.
(b) Identificación del fundador o fundadores.
(c) Dotación inicial.
(d) Fines y actividades determinados inicialmente por el fundador.
(e) Registro de fundaciones en el que está inscrita la fundación y protectorado de adscripción.


(f) Estatus fiscal: acogida a la Ley 49/2002, de 23 de diciembre (entidad beneficiaria del mecenazgo), o entidad parcialmente exenta.

(g) Domicilio social y sedes o delegaciones, en su caso.

(h) Estatutos vigentes de la fundación y otras normas de desarrollo (reglamento o códigos de buen gobierno, en su caso).

(i) Normativa básica por la que se regula la fundación.

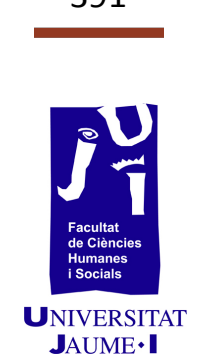

\section{Objeto}
(a) Descripción de la misión.
(b) Descripción de las áreas de actividad de la fundación.
(c) Descripción del colectivo o colectivos de beneficiarios.

\section{Estructura organizativa}

(a) Órganos de gobierno de la fundación -patronato y, en su caso, órganos delegados- $y$ otros órganos estatutarios unipersonales 0 colegiados existentes.

(b) Composición de los órganos anteriores y perfil y trayectoria profesional de sus miembros.

(c) Equipo directivo.

(d) Composición del equipo directivo y perfil y trayectoria profesional de sus miembros.

\section{Rendición de cuentas}

(a) Cuentas anuales: último balance, cuenta de resultados y memoria aprobadas por el patronato y remitidas al protectorado.

(b) Informe externo de auditoría en caso de auditarse voluntaria u obligatoriamente.

(c) Último plan de actuación aprobado por el patronato y remitido al protectorado.

\section{Políticas aprobadas por el patronato de la fundación}

(a) Gobierno corporativo.

La fundación señalará si cuenta con:

i. Marco estratégico.

ii. Prácticas o principios de buen gobierno.

iii. Mecanismos para evitar situaciones de conflicto de interés de los miembros de los órganos de gobierno.

(b) Criterios y procesos de control de la actividad.

La fundación señalará si cuenta con:

i. Procedimientos de aprobación de gastos.

ii. Criterios de selección de proyectos y de beneficiarios. 
iii. Sistemas de control y seguimiento interno de la actividad y de las aportaciones a los beneficiarios.

iv. Procedimientos de aceptación de donaciones y de relación con donantes y voluntarios.

\section{Otra información}

(a) Contratos firmados con una administración pública, con indicación del objeto, duración, el importe de licitación y de adjudicación y sus modificaciones.

(b) Relación de los convenios suscritos con una administración pública, con mención de las partes firmantes, su objeto, plazo de duración, modificaciones realizadas, obligados a la realización de las prestaciones y, en su caso, las obligaciones económicas convenidas.

(c) Encomiendas de gestión que se firmen con una administración pública, con indicación de su objeto, presupuesto, duración, obligaciones económicas y las subcontrataciones que se realicen con mención de los adjudicatarios, procedimiento seguido para la adjudicación e importe de la misma.

(d) Subvenciones y ayudas públicas recibidas con indicación de su importe, objetivo o finalidad y beneficiarios.

(e) Retribuciones agregadas percibidas anualmente por los patronos (2).

De manera más concreta, existen códigos deontológicos que proponen indicadores de carácter financiero para las ONG. Mencionamos el código de ética y conducta para las ONG de Wango, en el capítulo siete de su documento nos informa de que las fundaciones deberían llevar a cabo de manera legal, procedimientos financieros con orden para mantenerse legales y morales frente a sus miembros, donantes o sociedad acerca de sus inversiones. De esta manera serían reflejo de una organización responsable, confiable y que hace uso correcto de sus inversiones.

Además, propone que deberían llevar a cabo procedimientos financieros internos con total seguridad, cuidar sus informes económicos y ofrecer la posibilidad de revisar las declaraciones financieras de manera pública. Cabe añadir que es recomendable revisar periódicamente los registros financieros bajo auditores calificados que certifiquen la adecuada actuación de la organización.

De esta manera, Wango propone una cierta transparencia financiera y responsabilidad de las fundaciones observando de manera detallada los siguientes aspectos:

1. Responsabilidad fiscal. Los miembros del cuerpo directivo mantienen en última instancia la responsabilidad fiscal por la organización y han de entender los requerimientos o deberes de informar sobre las actas económicas o declaraciones financieras de la organización. 
2. Presupuesto anual. El presupuesto anual de la organización tiene que ser aprobado por el cuerpo directivo, y tiene que esbozar una proyección de gastos para las actividades programadas, recaudación de fondos y administración. La ONG tiene que operar en conformidad con este presupuesto.

3. Declaración financiera interna. La declaración financiera interna se debe preparar regularmente y suministrar al cuerpo directivo. Todas y cada una de las variaciones significativas entre el presupuesto de gastos y los desembolsos reales, y entre ingresos presupuestados y reales, han de estar identificadas y explicadas convenientemente por el cuerpo directivo.

4. Políticas financieras. La ONG deberá tener políticas financieras establecidas, idóneas para el tamaño de la organización, en lo referente a la recepción y al desembolso de recursos financieros, inversiones de bienes, prácticas adquisitivas, procedimientos de control interno (tales como políticas para la firma de cheques) y demás.

5. Procedimientos de control interno. Los procedimientos de control interno salvaguardarán a la organización contra una persona con poder de emitir cheques de que lo haga a su favor, y se requiere una firma adicional. Los procedimientos de control interno de la organización deberán servir a modo de salvaguarda ante una persona que pueda tener la capacidad de emitir un cheque por un monto superior a cierta cifra especifica (son necesarias dos firmas para emitir cheques por un monto superior a 5000 dólares estadounidenses) e implementará restricciones sobre los cheques extendidos como dinero para cobrar en caja.

6. Auditoría. Si la organización tiene un ingreso anual considerable, la exactitud de los informes financieros estará sujeta a una auditoría realizada por un calificado contable independiente. Las ONG que tengan un total de ingresos de monto reducido tendrán que ser revisadas por un calificado contable. Para las ONG con muy pocos ingresos, producidos internamente, bastará con una declaración financiera completa.

7. Niveles de profesionalidad. La organización se ceñirá a niveles de profesionalidad en los procedimientos contables y auditorias según estipulen las leyes en su nación, y cumplirá con los requerimientos sobre los informes financieros.

\subsection{Análisis del Tercer Sector}

Una organización no gubernamental (ONG) es la agrupación de ciudadanos que desean luchar por una causa y que no tienen fines lucrativos, es decir, que no se llevan ningún tipo de beneficio económico por ayudar a la causa a la que se dirigen.

Por tanto, una ONG se centra en la realización de actividades de carácter humanitario, y consigue trasladar los problemas de una 
sociedad hacia los gobiernos, supervisa las políticas que se llevan a cabo y promueve el aumento de la participación ciudadana.

Pueden estar organizadas en torno a temas más concretos, como son las que velan por los derechos humanos, la salud o el medioambiente.

El significado de ONG como tal se acuñó en la Carta de Naciones Unidas en el año 1945. En la actualidad, de forma aproximada, hay mundialmente un total de 10 millones de organizaciones no gubernamentales.

Existen ONG de carácter internacional puesto que, por desgracia, actualmente hay menores en todo el mundo que no son capaces, por temas económicos, de satisfacer sus necesidades básicas como es el poder alimentarse, acceder a una educación digna con posibilidades de ir a la escuela o simplemente de poder vivir en condiciones dignas.

Por tanto, las ONG han adquirido un papel activo, dominante en el sentido de que acuden a los niños en el lugar donde se encuentran.

Aproximadamente, para poder ofrecer una cifra, hay actualmente unos 66 millones de niños y niñas que no gozan de tener una buena alimentación por encontrarse en países que todavía están en desarrollo. De esta cifra nombrada, 23 millones viven en África.

Así pues, las ONG tienen que cumplir una serie de requisitos para poder llevar a cabo su actividad como el hecho de que no tengan ánimo de lucro, ya que si fuese así perderían credibilidad porque la gente que dona y colabora no sabría con certeza si el dinero que aporta llega al destino en forma de ayuda. Además, si se repartieran los beneficios no podrían ofrecer los fondos obtenidos en su plenitud a la causa.

Por otra parte, las ONG deben tener una capacidad de autogobierno, ya que son organismos independientes a la Administración Pública.

Este tipo de proyectos que son para el beneficio de la sociedad conllevan una serie de costes que deben asumir, y esto se convierte en un reto.

Una de las fuentes de financiación de las ONG son los fondos públicos. La Fundación "La Caixa", PriceWaterhouseCoopers y ESADE elaboraron en el año 2014 un informe en el cual indicaba que el 60 \% de los fondos que obtienen estas organizaciones provienen del sector público. Una de las conclusiones a las que llegaron es que este porcentaje con el paso del tiempo va a ir disminuyendo.

Además de este tipo de fondos, existe otro, que es el sector privado. Es decir, las empresas forman parte de un apoyo económico de las organizaciones. Mencionar también las colaboraciones de 
personas de carácter económico y de colaboración en forma de voluntariado.

\section{Marco empírico}

\subsection{Conclusión de los estudios}

Tras el análisis del estudio publicado en la revista Vivat Academia, el número de socios no influye en la presencia de las organizaciones en Internet, pero sí en el uso que le dan. Tanto las grandes ONG como las pequeñas, se encuentran en el espacio cibernético, pero las de mayor capacidad están sabiendo sacar más partido a dichas herramientas. Esto puede estar dado puesto que en las pequeñas ONG cada voluntario realiza cualquier tarea, mientras que en las grandes las funciones de cada uno pueden estar repartidas y centradas en un área concreta de la organización. Es posible que en estas últimas citadas haya una especie de community manager encargado de comunicarse, mediante la red, con los usuarios.

\subsection{Análisis web}

ALDEAS INFANTILES es una ONG de carácter internacional y privado, que ofrece ayuda sin ánimo de lucro sin ningún tipo de orientación política. Fue fundada en el año 1949 en Austria, y actualmente está presente en un total de 134 países. Esta ONG forma parte de la UNESCO y proporciona asesoría al Consejo Económico y Social de la ONU.

Se dedican a dar cuidado y protección a niños que no han tenido un cuidado parental, les dan un entorno familiar protegido en el cual puedan sentirse respetados y queridos durante su infancia. Además, realizan un seguimiento y se mantienen presentes en la vida del niño hasta que este logra ser una persona autosuficiente y se encuentra integrado en la sociedad.

En la página web se pueden ver diferentes apartados como son: "Quiénes somos», en el que hay subapartados como transparencia (ofrece en la web documentos de cuentas y memorias anuales a partir de 2014 hasta la actualidad, pero los informes de años anteriores no aparecen), misión, visión, valores y formas de contactar con ellos.

El segundo apartado que aparece en la página web es «Qué hacemos». En él, la organización ha establecido una serie de palabras clave con las que definen sus principales vías de actuación: protección, jóvenes, prevención, sensibilización, Aldeas en España y Aldeas por el mundo.

Por otra parte, el tercer apartado de la página se centra en lo que podemos hacer nosotros para colaborar («Qué puedes hacer 
tú»). Se muestran diferentes vías con las que poder ayudar a la ONG. También tiene una sección de lo que ocurre en la actualidad y un apartado de tienda en línea.

Así pues, en base a los códigos deontológicos, hemos realizado un análisis de la web ALDEAS INFANTILES para comprobar si realmente la organización cumple con los principios de transparencia.

En la web aparecen los criterios de constitución de la fundación y los datos identificativos de esta bastante completos. Además, sí que informan del destino de los fondos pero en cuanto a los criterios y procesos de control de la actividad de la organización no están tan completos. Por otro lado, no muestran los reconocimientos obtenidos por la organización y, en cuanto a la rendición de cuentas, se puede ver que a pesar de ser una organización fundada en el año 1949, tan solo figuran las memorias anuales de los años 2014, 2015 y 2016.

CASA CARIDAD es una ONG de carácter privado e independiente, fundada en el año 1906. No se declina hacia ningún tipo de orientación política ni religiosa. A lo largo del tiempo en el que lleva operando esta organización, han repartido más de 45 millones de comida, además de haber dado un lugar donde dormir a "cientos de miles de personas sin hogar».

En cuanto a los servicios que ofrece, en su página web encontramos un apartado en el que explican todas y cada una de sus vías de actuación. Son las siguientes: albergues, comedores sociales, escuelas infantiles, multicentro social, centro de día y programas de recuperación personal.

Por otro lado, también hay subapartados en la web en los que aparecen el personal que colabora con ellos, las formas de colaboración y las últimas noticias.

Haciendo referencia a si la fundación cuenta con suficiente información para cubrir los códigos deontológicos, se puede ver en primer lugar que no aparecen ni el año de fundación ni el destino al que van dirigidos los fondos. Además, tan solo aparece un informe financiero del año 2016, factor a cuestionar, porque es una de las ONG que menos información financiera muestra en su web. Por otro lado, no cuenta con una misión del imitada ni un código ético de buen gobierno.

PAYASOSPITAL es una organización no gubernamental fundada en el año 1997.

Por lo que respecta a su página web, ofrece información financiera básica antes de acceder a los documentos financieros desde 2014; aparecen dos gráficos circulares que aportan datos a modo de porcentajes acerca del origen de los fondos con los cuales la organización se financia y de la distribución de los ingresos que reciben. 
Ofrece un apartado muy completo sobre sus vías de actuación y sobre la identidad de la organización, así como noticias sobre los eventos a los que asisten.

Por otro lado, muestra dónde van los donativos que las personas realizan, además de las ventajas fiscales que obtienes si realizas una aportación. En términos de transparencia, en la página web hay un apartado en el que se muestran los resultados de las auditorías que les realizan anualmente y, la parte más humana de la organización, se ofrece cursos de formación para poder ejercer de payaso en un hospital.

De acuerdo con los códigos deontológicos, podemos ver una información completa en cuanto a la constitución de la fundación y sus datos identificativos, además de presentar una estructura de la organización completa. Cuenta con un código de buen gobierno pero la misión de la organización no aparece en la web. Por otra parte, en referencia a los resultados financieros, se puede cuestionar que aparezcan los informes de auditoría de los años 2015 y 2016 pero el de transparencia sea de los años 2014 y 2016. No aparecen en ningún lugar las cuentas anuales ni las memorias.

SAVE THE CHILDREN es una organización no gubernamental creada en 1919 con el fin de dar voz a los problemas que puedan surgir a niños y niñas durante su infancia en situaciones de pobreza en cuanto a la desnutrición, ya que busca erradicarla, al igual que la explotación infantil. Proporciona ayuda humanitaria para que no haya ningún niño ni ninguna familia que no tenga el principio de dignidad.

Consta de una web bastante completa en términos de transparencia -aunque se deba analizar mediante los códigos deontológicos-, ya que muestra las memorias y las cuentas anuales que tiene la organización, además de unos principios de «buen gobierno», ya que aparece un listado de documentos en los que dejan constancia de códigos éticos, de conducta, políticas de inversiones financieras y de prevención de fraude y corrupción... Por otra parte, hay una sección destinada a donativos. Puedes proponer retos para realizar, testamentos solidarios, la comunicación de las acciones que realizan...

Así pues, según el análisis elaborado utilizando los códigos deontológicos, se puede observar que, en cuanto a informes financieros, aparecen memorias desde el año 2013 hasta el 2016. Por otro lado, tiene una serie de políticas establecidas además de principios de buen gobierno y estatutos. No tiene informes de auditoría ni una misión clara, como tampoco figura el destino al que se dirigen los fondos ni el año de fundación, en cuanto a los datos identificativos de la organización. Se debe destacar que cuenta con un plan estratégico. 
AESCO es una organización fundada en 1991. Su propósito es la promoción de programas de carácter social con el fin de fomentar la solidaridad para el auxilio de colectivos que se encuentran en situaciones de vulnerabilidad, concretamente entre Europa y América Latina.

Tiene un apartado en el que figuran los servicios que se realizan como puede ser la ayuda en forma de banco de alimentos, ayuda jurídica, apoyo escolar, atención psicológica... Asimismo, tiene servicio de voluntariado y prácticas, además de noticias de actualidad por parte de la fundación.

Por otro lado, hay un apartado de transparencia $y$, a continuación, junto a la página web en general, se revisará si cumple los criterios que establecen los códigos deontológicos.

Así pues, la página web tiene un registro muy completo en cuanto al listado de sedes en las que se encuentra la organización. Asimismo, la estructura organizativa, además de los datos identificativos, también es completa.

Se puede observar, por el contrario, que no existen Estatutos ni criterios de buen gobierno, además de que no aparece en ningún lugar el destino al que van dirigidos los fondos. En referencia a los informes financieros de la organización, extraña que tan solo aparezcan las cuentas anuales del año 2015 y la memoria de actividades desde 2012 hasta 2015, es decir, la información financiera no está actualizada.

ASPANION fue fundada en 1985 y ayuda a familias con niños con cáncer. Tiene sede en Valencia y Alicante, y anualmente se encarga de entre 130 y 140 casos de niños con edades comprendidas entre 0 y 18 años que han sido tratados y diagnosticados en una de las tres unidades de referencia de oncología pediátrica de la Comunidad Valenciana. La ONG forma parte de la Federación Española de Padres de Niños con Cáncer, de la Plataforma de Entidades de Voluntariado de la Comunidad Valenciana y de la Alianza General de Pacientes.

Mediante la web se puede acceder a la hoja de reclamaciones de la organización; también ofrece información acerca del organigrama, los estatutos legales, las actividades anuales, el informe de auditoría, el RSC, la política de comunicación y de calidad, posee un código deontológico propio y un plan estratégico.

Desde 2008 ASPANION forma parte del programa de la Fundación "La Caixa" para la atención integral a personas con enfermedades avanzadas y sus familiares. Cabe añadir que colabora con otras asociaciones como FEPNC, AOEX, AFANOC y la Fundación Enriqueta Villavecchia, así como con entidades entre las que se encuentran Iberdrola, Ajuntament d'Alzira, Orona, Obra Social "La Caixa", BBVA, Diputació de València, Consum, Generalitat Valenciana, CVF, etc. 
Ofrece un apartado de calidad y buenas prácticas en el que podemos encontrar diferentes documentos como por ejemplo la política de calidad, la política de comunicación, la RSC y el informe de auditoría de cuentas anuales; aunque solamente de 2016.

$\mathrm{Si}$ analizamos la web bajo los criterios que presenta el código deontológico de $A E F$, detectamos que Aspanion refleja cada uno de los puntos que propone el código ético del apartado que trata sobre la constitución y los datos identificativos de la ONG. En cuanto al objeto, la fundación presenta tanto su misión en la sociedad como la actividad que lleva a cabo, cada uno de los premios que se le ha otorgado y el colectivo al cual va destinada la ayuda ofrecida.

En uno de sus despliegues se puede encontrar un esquema de la estructura organizativa, pero de manera general. Por lo que respecta a las cuentas, la ONG solamente presenta el último documento realizado de las cuentas anuales; si lo analizamos, detectamos que presenta el balance de situación, sus cuentas de resultados, la memoria de la organización, la situación fiscal e incluso las deudas. Aunque solo presente el informe de auditoría de las cuentas anuales de 2016, podemos corroborar que es completo y que presenta todos los datos financieros necesarios para considerarse lo suficientemente transparente. Sigue una política de calidad y presenta un apartado de reclamaciones para todo aquel que tenga la necesidad de poner una queja a la ONG.

ONG PROYSO, creada en 1996 tras la colaboración con el Centro Infantil Luis Amigó, persigue el fin de solidarizarse con los niños más empobrecidos del Tercer Mundo, en concreto en Guinea Ecuatorial. Está inscrita en el Registro de Asociaciones del Ministerio de Justicia e Interior. Llevan a cabo un proyecto con el objetivo de atender las necesidades nutritivas y educativas de los niños acogidos en el Centro Nutricional Luis Amigó en Evinayong, además de atender sanitariamente a las comunidades de alrededor.

Colabora con diferentes instituciones y empresas de la Comunidad Valenciana, algunas de las cuales son parroquias o centros educativos religiosos.

Tras analizar la página web, se puede observar que la información es escasa; hay muchos apartados que se repiten en más de una ocasión y en ningún desplegable aparecen documentos financieros que corroboren los movimientos de capital de la organización.

$\mathrm{Si}$ ponemos en práctica el código deontológico de $\mathrm{AEF}$, específicamente el apartado que habla de rendición de cuentas, ni se detectan las cuentas anuales, ni el informe externo de auditoría, ni tienen el último plan de actuación aprobado por el patronato y remitido al protectorado...

FARMAMUNDI, fundada en 1991 por un grupo de farmacéuticos en Valencia, es la primera organización no lucrativa de todo el país 
en suministrar y ayudar mediante fármacos a organizaciones humanitarias y a países en vías de desarrollo. Trabaja en colaboración con socios locales, en su web se puede observar de manera detallada de dónde provienen sus finanzas, las área de proyectos de desarrollo, el área de acción humanitaria y de emergencia, ALH.

Se puede observar que la plataforma está totalmente completa, encontramos todo tipo de información que puede ayudar al público a confiar en esta ONG y, además, da la opción de revisar la información en diferentes idiomas.

Si analizamos el apartado de transparencia, podemos detectar que presenta el origen de las subvenciones y el destino de los recursos mediante un diagrama circular, en el que se divide por sectores el porcentaje de las subvenciones que obtienen de entidades privadas o públicas. Además, proporciona los estatutos mediante un enlace desde el cual se pueden descargar descargable y las cuentas anuales desde 2009 hasta 2016.

Cabe añadir que presenta todas aquellas auditorías y calificaciones que han regulado cada práctica que la organización ha llevado a cabo, también las certificaciones, nacionales e internacionales, que acreditan la actividad de la ONG y los códigos éticos que han seguido para contrarrestar la transparencia. Se observa toda la información relacionada con la constitución de la fundación y datos identificativos, su misión y área de actividad, la estructura organizativa de la ONG de manera detallada, la rendición de cuentas y la auditoría externa. Si analizamos el último documento de auditoría, encontramos que presenta un balance de situación, la cuenta de resultados y la memoria. Por último, cabe añadir que presenta los sistemas de gestión internos, por ejemplo el marco estratégico y diversas políticas de gestión.

FUNDACIÓN ANAR. Tras un breve análisis de su página web, observamos que lleva ejerciendo desde hace 47 años tanto en España como en Sudamérica, dedicada a ayudar a niños y adolescentes con riesgo social. Opera junto con otras asociaciones y plataformas, y sus cuentas anuales están auditadas por Audit Buró, S. L. y depositadas en el Protectorado de Fundaciones del Ministerio de Sanidad, Servicios Sociales e Igualdad.

El sitio web de la ONG está bastante completo, se puede encontrar cualquier tipo de información de manera clara y rápida. Alguno de los desplegables que hemos considerado importantes son, por ejemplo, el de agradecimiento. Fundación Anar está respaldada por patrocinadoras, protectoras, colaboradoras, administraciones públicas y por comunidades autónomas y ayuntamientos.

Además lleva a cabo estudios, campañas contra el bullying, contra la violencia de género, participa en asambleas de carácter 
internacional, se implica en el deporte, con las diferentes disciplinas artísticas, etc.

Si nos basamos en los códigos deontológicos propuestos, figuran todos los apartados propuestos en la constitución de la fundación y los datos identificativos del código deontológico de AEF, así como su objeto en la sociedad (misión, visión, descripción de las áreas de actividad, etc.). De manera clara, se observa la estructura organizativa de la fundación y cada uno de los socios que pertenecen a esta. Por lo que respecta a la rendición de cuentas, la ONG presenta de manera exclusiva, en uno de sus apartados, los informes anuales desde 2014 hasta la actualidad. Además presentan cada informe anual de manera separada por casos, y las memorias de 2015 y 2014. Exponen cada movimiento financiero y a qué va destinado, pero no se refleja un balance de situación. Asimismo, informa que las cuentas anuales están auditadas, pero no presenta los documentos; lleva a cabo un control de los procesos de actuación, pero no ofrece ningún código deontológico ni el marco estratégico a seguir.

\subsection{Justificación de la muestra escogida}

Hemos elegido como objeto de estudio todas las ONG que operan en la provincia de Valencia puesto que residimos cerca de esta comunidad y nos es de gran interés analizar el Tercer Sector, concretamente el sector infantil; consideramos que son un tipo de ONG que actualmente está perdiendo fuerza en cuanto a fondos de financiación debido a que se está generando cierta desconfianza por parte de la sociedad.

Además pensamos que las organizaciones que ayudan a este colectivo tan vulnerable deberían ajustarse a códigos éticos aprobados y fiables que les otorguen credibilidad; al ser un sector poco considerado en cuanto a capacidad de respuesta, no tienen la posibilidad de defender sus derechos. Deben ser respetados igual que cualquier otro ser humano y para ello las ayudas que estas organizaciones les proporcionan deben ser verídicas, si no, nos encontraríamos en un contexto en el que fundaciones que tienen poder y gran peso para mejorar la calidad de vida de este colectivo se estarían aprovechando de una situación desfavorecida.

Las buenas prácticas son fundamentales para actuar de manera responsable en una sociedad en la que nos vemos envueltos en grandes estafas constantemente, por ello, este tipo de organizaciones tiene que ser sincero en cuanto a la destinación del capital, pues actualmente es muy difícil obtener fondos porque se ha generado una mala reputación contra las ONG que la sociedad considera inaceptable. 


\subsection{Método escogido}

En cuanto al método escogido para poder analizar la muestra de organizaciones no gubernamentales y así poder comprobar su transparencia en materia de comunicación financiera, hemos comprobado a través del código deontológico que propone AEF si las páginas web de estas ONG cumplen con el contenido que deberían tener publicado.

En líneas generales, propone seis puntos globales que deben reflejar o llevar a cabo cada una de las ONG para mostrar de manera completa toda la información que se considera necesaria para el público o la gente que va a colaborar, la constitución de la fundación y los datos identificativos, objeto, estructura organizativa, rendición de cuentas, políticas aprobadas por el patronato de la fundación y otra información. En concreto, hemos considerado más oportuno analizar de manera minuciosa el apartado de rendición de cuentas.

Así pues, el código ético sugiere detallar las cuentas anuales (último balance, cuenta de resultados y memoria aprobadas por el patronato y remitidas al protectorado.), el informe externo de auditoría y el último plan de actuación que ha aprobado el patronato y se ha remitido al protectorado. Puesto que nuestra hipótesis afirma que todas las ONG del sector infantil que operan en Valencia son transparentes en materia de comunicación financiera, debemos basarnos en un código referente para analizar si lo están siendo o no.

Así pues, meditamos que la Asociación Española de Fundaciones es una institución totalmente fiable, especializada en el sector y que, además, lo propuesto en el código de buenas prácticas es fácilmente detectable y tiene ítems imprescindibles para considerar si son transparentes o no en materia de comunicación financiera.

\section{Resultados}

Tras realizar la investigación y comprobación de que las páginas web de esta muestra de ONG infantiles cumplen con los principios de transparencia que propone el código deontológico de $A E F$, podemos concluir a grandes rasgos una serie de hechos que vienen dados en el marco teórico.

Así pues, hemos comprobado que hay que tener en cuenta que una ONG contenga información escasa por lo que respecta a la publicación de documentos financieros de años anteriores, pues genera desconfianza. Esto es así porque actualmente, en esta sociedad, las personas tienen cierto rechazo hacia este tipo de organizaciones ya que se han dado muchos casos en los que ha salido a la luz la destinación real de los fondos que recaudan de las personas que deciden colaborar. Por tanto, consideramos de vital importancia que las ONG publiquen la mayor cantidad de 
información financiera de la que dispongan y, a ser posible, de la mayor cantidad de años anteriores al que estamos, lo que permite que la sociedad compruebe las buenas prácticas que han llevado a cabo hasta hoy.

Además, otro de los factores que hemos observado es que se encuentran datos confusos en cuanto a la destinación de los fondos que recibe la mayoría de estas organizaciones. Creemos que se deberían concretar mucho más para que la gente que colabora o que quiere colaborar se sienta segura de que la ayuda que proporcionan llega al destino que la ONG asegura que va a llegar, ya que así harán que los donantes se sientan más partícipes.

Por otro lado, un punto positivo es que todas muestran su razón de ser y la estructura interna de organización que la compone. Pensamos que es un factor muy importante que tengan esto publicado, ya que dan conocer que realmente la organización es la que es y que no tienen problema en mostrar su identidad y su forma de proceder; operan correctamente.

Otro punto que queremos destacar es que todas las ONG analizadas, a excepción de una, muestran algún documento de cuentas anuales. Consideramos que es muy importante que las tengan publicadas y se pueda acceder fácilmente a estos documentos para tener una base fiable con la que sostener la estructura de la organización. Esta única ONG que no tiene en su web esta información nos ha proporcionado una futura línea de investigación, pues es la única de las que hemos analizado que no tiene información financiera y es de carácter religioso.

\section{Conclusión}

En conclusión, tras haber realizado una investigación profunda para comprobar la transparencia en materia de comunicación financiera, cabe decir que las ONG, para llevar a cabo su actividad dentro del Tercer Sector y ejercer el buen gobierno, tienen que cumplir un gran número de condiciones $y$, además, han de considerarse completamente transparentes.

Gracias a los códigos deontológicos hemos podido ver que en su gran mayoría siguen los principios de buen gobierno y aparentemente operan de forma correcta, a pesar de que en algunas organizaciones sí que hayamos visto que faltan pequeños datos, pero no demasiado relevantes; en general sí que contienen información bastante completa. Cabe destacar que hemos considerado que la ONG Farmamundi es la más completa y, por ello, la hemos tomado como referencia de buenas prácticas, por lo que, hemos partido de esta para analizar el resto de organizaciones.

Por otro lado, Proyso es la única organización que no muestra ningún tipo de documento financiero. Nos pusimos en contacto con 
la ONG a través de Twitter pero no recibimos ninguna respuesta por su parte. Además, es de las pocas, o la única, de carácter religioso; colabora con diferentes parroquias y asociaciones religiosas.

Así pues, refutamos nuestra hipótesis ya que, a pesar de que las ONG contienen en sus páginas web información bastante completa, son pocas las que proporcionan datos financieros necesarios para afirmar o considerar que son transparentes en cuanto a comunicación financiera publicada en su sitio web.

Opinamos que todas las organizaciones no gubernamentales deberían ser totalmente transparentes y sobre todo en materia de comunicación financiera; no es extraño que haya gran cantidad de personas desconfíe y, por tanto, no colabore. Son organizaciones con gran poder para cambiar parte de la sociedad; son las mediadoras entre la sociedad y el colectivo afectado que necesita ayuda, en concreto, económica. Por tanto, si llevaran a cabo unas prácticas transparentes, los que tienen impulso de ayudar podrían decidirse a hacerlo y a colaborar con causas que realmente necesitan asistencia social (además de que es muy importante conocer aquello con lo que van a contribuir económicamente).

\section{Futuras líneas de investigación}

Tras la realización del trabajo, nos hemos quedado con ciertos temas que han surgido durante la investigación. Así pues, hemos encontrado futuras líneas en las que enfocar otras nuevas.

La primera que hemos establecido es el estudio de la percepción que tiene la ciudadanía acerca de la distribución de los fondos de las ONG. Consideramos importante saber el origen del problema que tiene mucha gente con este tipo de organizaciones, pues piensa que no son sinceras con la destinación de los fondos. Por tanto, creemos que es relevante conocer los motivos para poder tratar de solucionar este problema.

La segunda línea de investigación que proponemos es el posible estudio de la publicación en materia de comunicación financiera de ONG que operen en otros ámbitos, como las que se dedican a ayudar a personas con enfermedades mentales, discapacitadas 0 drogadictas, con el fin de comparar y así saber si otros tipos de ONG cumplen igual que las infantiles los principios de transparencia de comunicación financiera.

La tercera línea de investigación que establecemos es el análisis de la influencia que puede tener o no el carácter laico o religioso de las organizaciones en cuanto a la opacidad en materia financiera, ya que, tras la investigación, como hemos dicho anteriormente, de todas las ONG analizadas, la más opaca en cuanto a proporcionar documentos financieros en la web es de carácter religioso. Por tanto, 
consideramos que sería interesante comprobar si hay más casos en los que se cumple esta coincidencia.

Por último, la cuarta línea de investigación que hemos encontrado a raíz de la elaboración del trabajo es la posibilidad de comprobar si la accesibilidad a los informes financieros en las páginas web influye de algún modo en la predisposición a colaborar, ya que en muchos casos hemos visto complejo el acceso a los documentos, incluso algunos no tenían el nombre como tal en la web para poder buscarlos o la información estaba dentro de otros documentos, y esto podría afectar a la voluntad de los donantes.

\section{Bibliografía}

Almansa Martínez, Ana, y María Jesús Fernández Torres. 2011. "Estudio sobre la Comunicación digital de las organizaciones sociales en España». Vivat Academia 117: 337-352.

Asociación Española de Fundaciones. s.d. "Buen gobierno y transparencia del sector». AEF. http://www.fundaciones.org/servicios/buen-gobiernotansparencia-sector.

Asociación Mundial de Organizaciones No Gubernamentales. s.d. "Código de ética y conducta para las ONG». WANGO. http://www.wango.org/codeofethics/COESpanish.pdf.

Castellano, Nicolás. 2017. «Una ONG subvencionada por el Gobierno mantiene a refugiados y toxicómanos en un mismo centro». Ser, 3 de enero.

Cooperating volunteers. s.d. "Cómo se financian las ONG». https://www.cooperatingvolunteers.com/home/como-sefinancia-las-ongs/.

Costa, Joan. 2009. Dircom, estratega de la complejidad. Nuevos paradigmas para la dirección de la comunicación. Barcelona: Aldea Global.

Elisaltarina. 2010. «¿Qué es y quiénes forman el Tercer Sector? Definición, características y retos "mensaje en un blog"». Economía Urbana, 15 de agosto. https://economiaurbana.wordpress.com/2010/08/15/reflexione s-en-torno-al-tercer-sector/

Foro internacional de las Plataformas Nacionales de ONG (FIP). 2016. «24 datos y estadísticas sobre las organizaciones no gubernamentales de todo el mundo». http://ifpfip.org/es/english-25-facts-and-stats-about-ngos-worldwide/.

García, Manuel. s.d. "ONG y Tercer Sector "mensaje en un blog"». Blog de cooperación internacional y acción social». Asociación 
Proade. https://www.asociacionproade.org/blog/ong-y-tercersector/.

Oxfam Intermón. s.d. "ONG internacionales que trabajan por la infancia "mensaje en un blog"». Ingredientes que suman. https://blog.oxfamintermon.org/ong-internacionales-quetrabajan-por-la-infancia/.

Ruíz, Víctor. 2012. "Las ONG que reciben más del $80 \%$ de sus ingresos en subvenciones, ¿son realmente "no gubernamentales"?». ForumLibertas.com. http://www.forumlibertas.com/las-ong-que-reciben-mas-del-80de-sus-ingresos-en-subvenciones-son-realmente-nogubernamentales/.

Sitios web de cada ONG

Aldeas Infantiles. 2017. Acceso del 13 de octubre de 2017. http://www.aldeasinfantiles.es/

Casa Caridad. 2017. Acceso del 13 de octubre de 2017. https://casacaridad.com/ Payasospital. 2017. Acceso del 13 de octubre de 2017. http://www.payasospital.org/ SAVE The Children. 2017. Acceso del 17 de octubre de 2017. https://www.savethechildren.es/

AESCO. 2017. Acceso del 17 de octubre de 2017. http://ongaesco.org/

Aspanion. 2017. Acceso del 17 de octubre de 2017. http://aspanion.es/

ONG Proyso. 2017. Acceso del 17 de octubre de 2017. http://ongproyso.es

Farmamundi. 2017. Acceso del 13 de octubre de 2017. http://www.farmaceuticosmundi.org/farmamundi/

Fundación Anar. 2017. Acceso del 17 de octubre de 2017. https://www.anar.org/ 